OPEN ACCESS

Edited by:

Ke-Wu Zeng,

Peking University Health Science

Center, China

Reviewed by:

Gang Fan,

Chengdu University of Traditional

Chinese Medicine, China

Lei Chen,

Fujian Agriculture and Forestry

University, China

*Correspondence:

Yue Liu

liuyueheart@hotmail.com

Luqi Huang

huangluqi01@126.com

Specialty section:

This article was submitted to

Ethnopharmacology,

a section of the journal

Frontiers in Pharmacology

Received: 10 December 2020

Accepted: 10 February 2021

Published: 19 March 2021

Citation:

Li Y, Liu Y, Cui J, Zhao H, Liu Y and Huang $L$ (2021) Cohort Studies on Chronic Non-communicable Diseases Treated With Traditional Chinese Medicine: A Bibliometric Analysis.

Front. Pharmacol. 12:639860. doi: 10.3389/fphar.2021.639860

\section{Cohort Studies on Chronic} Non-communicable Diseases Treated With Traditional Chinese Medicine: A Bibliometric Analysis

\author{
Yiwen $L^{1,2,3}$, Yanfei Liu ${ }^{4}$, Jing Cui ${ }^{1,3}$, Hui Zhao ${ }^{2}$, Yue Liu ${ }^{1,2,3 *}$ and Luqi Huang ${ }^{2 *}$ \\ ${ }^{1}$ Cardiovascular Center of Xiyuan Hospital, China Academy of Chinese Medical Sciences, Beijing, China, ${ }^{2}$ China Center for \\ Evidence-based Medicine of TCM, China Academy of Chinese Medical Sciences, Beijing, China, ${ }^{3}$ National Clinical Research \\ Center for TCM Cardiology, Beijing, China, ${ }^{4}$ Institute of Clinical Pharmacology of Xiyuan Hospital, China Academy of Chinese \\ Medical Sciences, Beijing, China
}

Cohort studies investigating the treatment of chronic non-communicable diseases (NCDs) with traditional Chinese medicine (TCM) have considerably accumulated in recent years. To systematically and for the first time present the achievements and dilemmas of cohort studies, strict inclusion and exclusion criteria were used to search publications from the Web of Science, PubMed, Embase, Cochrane Library, and China National Knowledge Infrastructure databases for cohort studies on NCDs with TCM since the establishment of these databases. Information on the year of publication, exposure factors, diseases, and outcome indicators was obtained, and a literature quality assessment and bibliometric descriptive analysis were conducted. A total of 182 published articles involving 1,615,106 cases were included. There were 110 non-prospective cohort studies and 72 prospective cohort studies. The diseases involved in the cohort studies were, in the order of the number of published articles, malignant tumors (82 articles, 45.05\%), cardiovascular diseases (35 articles, $19.23 \%$ ), neurological diseases (29 articles, 15.93\%), chronic kidney diseases (16 articles, 8.79\%), liver cirrhosis (8 articles, 4.40\%), diabetes mellitus (8 articles, $4.40 \%$ ), and chronic respiratory diseases (4 articles, $2.20 \%$ ). The study participants were mainly from China (177 articles, 97.25\%). The number of cohort studies increased significantly in the last 5 years (65 articles, 35.71\%), and following the Newcastle-Ottawa Scale (NOS) literature quality evaluation, the number of articles that received a score of four to five was high (116 articles, 63.73\%), and the overall quality needs to be improved. The application of cohort studies in the field of TCM for the prevention and treatment of NCDs has developed rapidly in the past 5 years, focusing on the prevention and treatment of tumors as well as cardiovascular and cerebrovascular diseases. However, the design and implementation of cohort studies still have considerable limitations. To provide more clinical evidence, researcher should actively cooperate with evidence-based methodologists and standardize the implementation of cohort studies.

Keywords: cohort study, chinese medicine, bibliometric analysis, non-communicable diseases, evidence-based medicine 


\section{INTRODUCTION}

Chronic non-communicable diseases are a group of chronic conditions other than acute infections or parasitic injuries, maternal and perinatal conditions, or nutritional deficiencies (Wagner and Brath, 2012). With global economic development and modernization, the economic burden has shifted from communicable diseases to NCDs (Omran, 1971). NCDs are the leading cause of death globally, accounting for $71 \%$ (41 million) of the 57 million deaths worldwide in 2016, and the number is expected to increase further (World Health Organization, 2018a). Cancer, cardiovascular diseases, diabetes, and chronic respiratory diseases account for the highest morbidity, mortality, and disability rates (World Health Organization, 2018b). Such a huge impact on individuals and the society has hastened the need for the prevention and control of NCDs with multiple therapies.

As complementary and alternative medicine is widely used in Asia and has a global impact, the role of traditional Chinese medicine (TCM) in the prevention and treatment of chronic NCDs has received increasing attention worldwide, and approximately $61 \%$ of anticancer drugs and $50 \%$ of cardiovascular drugs were developed from natural herbal products in recent years (Newman and Cragg, 2020; Zhao et al., 2020), especially since the Nobel Prize was awarded for research on artemisinin from TCM (Ma et al., 2020). Natural products and natural product-derived compounds have proven to be effective and to have a mechanism against NCDs. The interaction and overlap of pathways in different diseases had made the use of the same TCM treatment for different diseases possible (Huang et al., 2018; Zhang and Wei, 2020). Since the outbreak of the coronavirus 2019 (COVID-19) epidemic that swept across the world in early 2020, integrated medicine therapies have played a tremendous role in the rapid control of this epidemic in China (Hu et al., 2020). In recent years, the effect of TCM on preventing and treating chronic NCDs and improving the clinical prognosis of some diseases has been confirmed by an increasing number of clinical studies (Hershman et al., 2018; Yang et al., 2012).

Cohort studies are suitable for obtaining outcomes that are closest to real-world TCM practice, with characteristics such as a long treatment cycle and an individualized treatment plan (Liu, 2007). In recent years, the number of cohort studies in the field of TCM has shown a significantly growing trend, involving many diseases especially NCDs. The clinical practice and effects of TCM have been emphasized in cohort studies, although the quality of research needs to be improved. Cohort studies in the field of TCM are mostly interventional cohort studies, i.e., with TCM (including TCM formulas, acupuncture, etc.) treatment as the exposure. A specific population is divided into exposure and non-exposure groups, and the differences in the incidence of the endpoint events between the groups are tracked and observed for a period of time, in order to further evaluate the clinical efficacy of the prevention and treatment of major diseases (Zhang et al., 2019). No randomization is used in these studies, and the willingness of subjects to receive treatment is monitored, with an increased subject compliance, a long follow-up period, and favorable longterm endpoint indicators.

This paper considers the prevention and treatment of chronic NCDs as a research entry point, summarizes and conducts a bibliometric analysis on the current status of cohort research in the field of TCM over the past 2 decades, and discusses the scope for future research.

\section{MATERIALS AND METHODS}

\section{Retrieval Strategy}

The Web of Science, PubMed, Embase, Cochrane library, and China National Knowledge Infrastructure (CNKI) databases were searched on a computer for literature from the time the databases began to include journal articles to October 1, 2020. The English search terms were Chinese medicine, acupuncture, herb, herbs, alternative therapy, complementary therapy, and cohort study. The Chinese search terms were zhen jiu (acupuncture), zhen ci (needle puncture), dian zhen (electroacupuncture), ai jiu (moxibustion), tui na (manipulation), zhong yi (TCM), zhong yao (traditional Chinese materia medica), zhong $x i$ yi jie he (integrated traditional Chinese and Western medicine), zhong cheng yao (traditional Chinese patent medicine), tang (decoction), fang (formula), and dui lie yan jiu (cohort study). The retrieval formula was appropriately adapted to different databases.

\section{Inclusion Criteria}

1) The study design was a cohort study; 2) The study had a clear classification of the exposure and non-exposure groups; 3) The exposure factors of the study were related to TCM interventions, which were defined as various dosage forms of TCM formulas, acupuncture, manipulation, etc.; 4) The study endpoints should be related to important NCDs; NCDs included in this study included malignant tumors, cardiovascular diseases (coronary artery disease, atherosclerotic heart disease, heart failure, hypertension), respiratory diseases (chronic obstructive pulmonary disease, asthma), diabetes and related complications, liver cirrhosis, chronic kidney disease (diabetic nephropathy, chronic renal insufficiency), and neurological diseases (stroke, Alzheimer's disease, dementia); and 5) The language is limited to Chinese or English.

\section{Exclusion Criteria}

(1) Duplicate publications or articles with only an abstract and no access to the full text;

(2) articles claiming to be cohort studies but were found to be randomized controlled studies, case-control studies, or crosssectional studies after reading the full text.

\section{Data Extraction}

Literature management was performed using the EndnoteX9 software. Data were extracted using a pre-defined data collection form and entered using epidata 3.1 software.

Information extracted included the year of publication, language of publication, region in which the study was conducted, type of cohort study reported in the article (including prospective, retrospective, and ambispective cohort studies), sample size, 


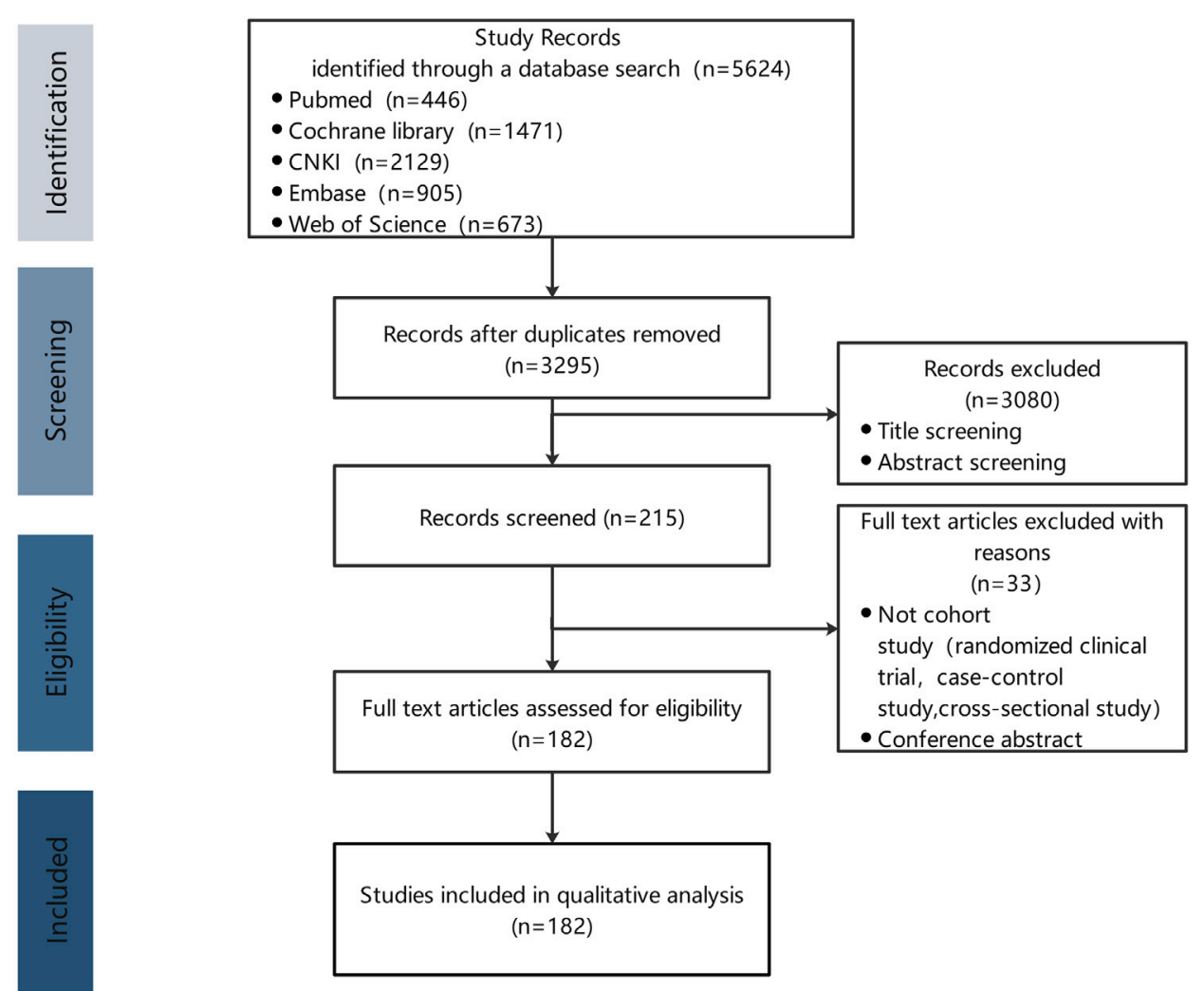

FIGURE 1 | Flowchart of the literature search and study selection.

exposure factors for the observation groups, disease-states studies (classified according to the 11th revision of the International Statistical Classification of Diseases and Related Health Problems, ICD-11 (Lancet, 2019)), and observation indicators.

The methodological quality of each cohort study was evaluated according to the Newcastle-Ottawa Scale (Stang, 2010) item-by-item, and a total score was calculated, which was proportional to the quality of the study. The NOS scoring was done by two evaluators separately. Disagreements were resolved by further reference to the original text and by consensus, and if not, a qualified third person was asked to evaluate the study.

\section{Data Statistics}

This study used EXCEL 2007 (Microsoft Corporation, Redmond, WA, United States) to classify, descriptively analyze, and report the data extracted from the literature. Edrawsoft 9.4 was used to draw the figures.

\section{RESULTS}

\section{General Information of the Included Articles}

A total of 5,624 articles were retrieved and screened according to the inclusion and exclusion criteria, and 182 articles were finally included in this study for analysis (Figure 1).
A total of 89 English articles (48.90\%) and 93 Chinese articles (51.10\%) were included. There were 72 prospective (39.56\%), 91 retrospective studies (50\%), 4 ambispective $(2.20 \%)$ cohort studies, and 15 inadequate trial reports (8.24\%). From the 182 articles, a total of $1,615,106$ cases were included in this study. Among the 21 articles (11.54\%) with the number of cases $>10,000$, one was from South Korea, while all the others were from Taiwan. There were 25 articles (13.74\%) with $10,000 \geq$ number of cases $>1,000,22$ articles $(12.08 \%)$ with $1,000 \geq$ number of cases $>500,81$ articles (44.51\%) with $500 \geq$ number of cases $>100$, and 33 articles (18.13\%) with 100 cases $\geq$ number of cases $>0$.

The implementation regions included Asia, Europe, and North America. There were 177 articles from China (119 from Chinese Mainland, two from Hong Kong, and 56 from Taiwan), and 5 articles were from other countries (1 from South Korea, 2 from the United States, 1 from Germany, and 1 from France). Few articles were published before 2015 and were mainly published in Chinese journals; since 2015, the number of published articles has surged, and the proportion of English articles has increased (Figure 2).

\section{Exposure and Endpoints in the Included Articles}

The diseases involved include malignant tumors (lung cancer, gastric cancer, colorectal cancer, liver cancer, breast cancer, 


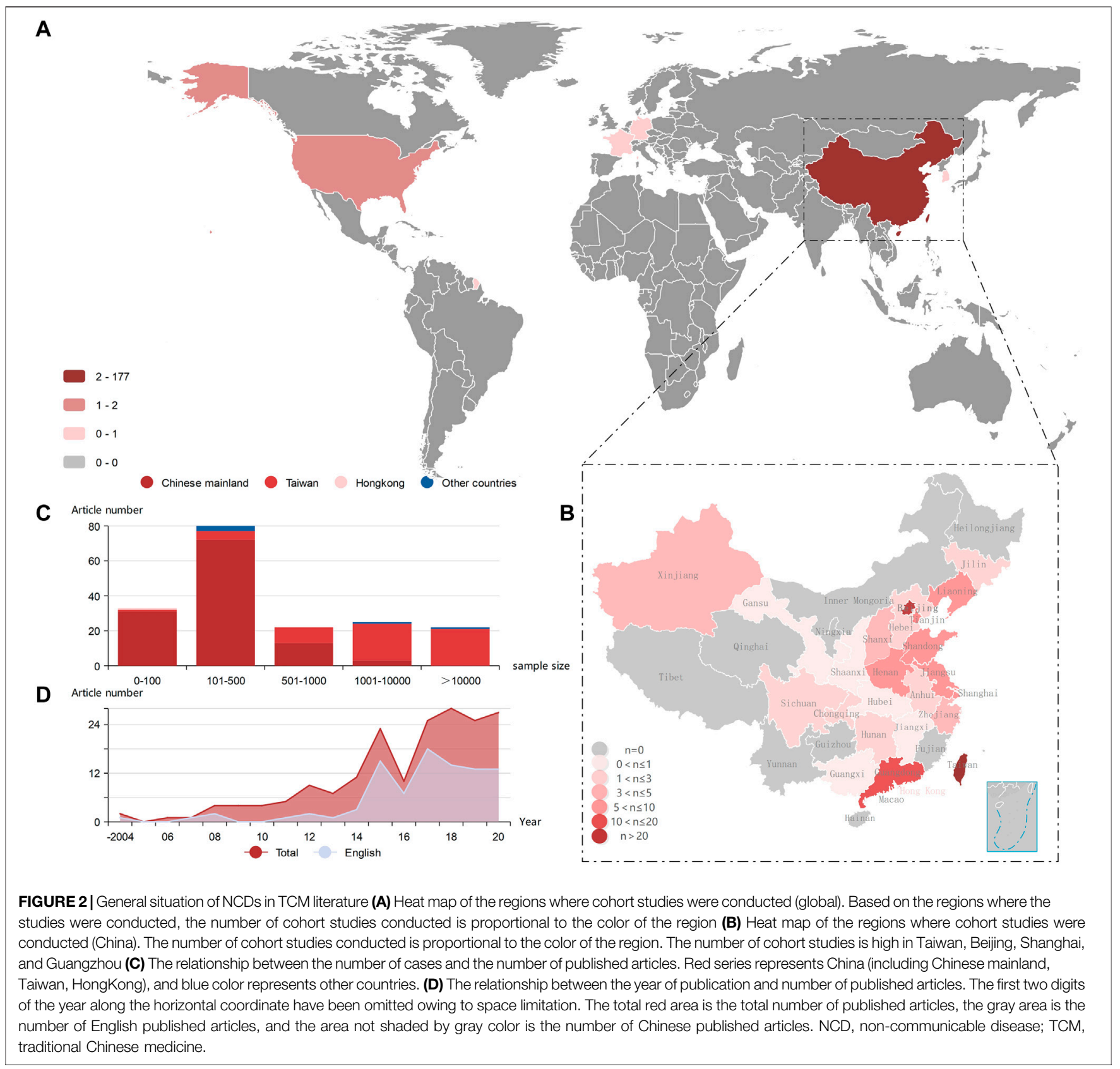

gynecological cancer, prostate cancer, head and neck cancer, pancreatic cancer, and leukemia), cardiovascular diseases (coronary atherosclerotic heart disease, hypertension, and dilated cardiomyopathy), neurological diseases (stroke, Alzheimer's disease, and dementia), chronic respiratory diseases (chronic obstructive pulmonary disease, and asthma), liver cirrhosis, chronic kidney diseases (chronic renal failure of all cause), and type 2 diabetes. Among the above-mentioned diseases, tumors are hotspots, followed by cardiovascular and neurological diseases. There were 15 articles (8.24\%) in the literature describing TCM interventions aimed at reducing the incidence of NCDs, 167 $(91.76 \%)$ articles describing the therapeutic effects on major diseases, 82 articles (45.05\%) on malignancy, 35 articles (19.23\%) on cardiovascular diseases, 29 articles (15.93\%) on neurological diseases, 16 articles $(8.79 \%)$ on chronic kidney diseases, 8 articles $(4.39 \%)$ on liver cirrhosis, 8 articles $(4.39 \%)$ on diabetes mellitus, and 4 articles $(2.19 \%)$ on chronic respiratory diseases (Figure 3 ).

The specific TCM interventions in the included articles were TCM decoctions, patent medicines (including effective extracts), TCM formula injections, acupuncture, and other interventions (manipulation, TCM formula transdermal patches, TCM formula enemas, and TCM formula plasters). Among them, 35 articles that did not specify the mode of exposure (without specifying the TCM intervention measure used), 85 articles used TCM decoctions, 32 articles used patent medicines, 10 articles used TCM injections, 27 articles used acupuncture as the mode of 


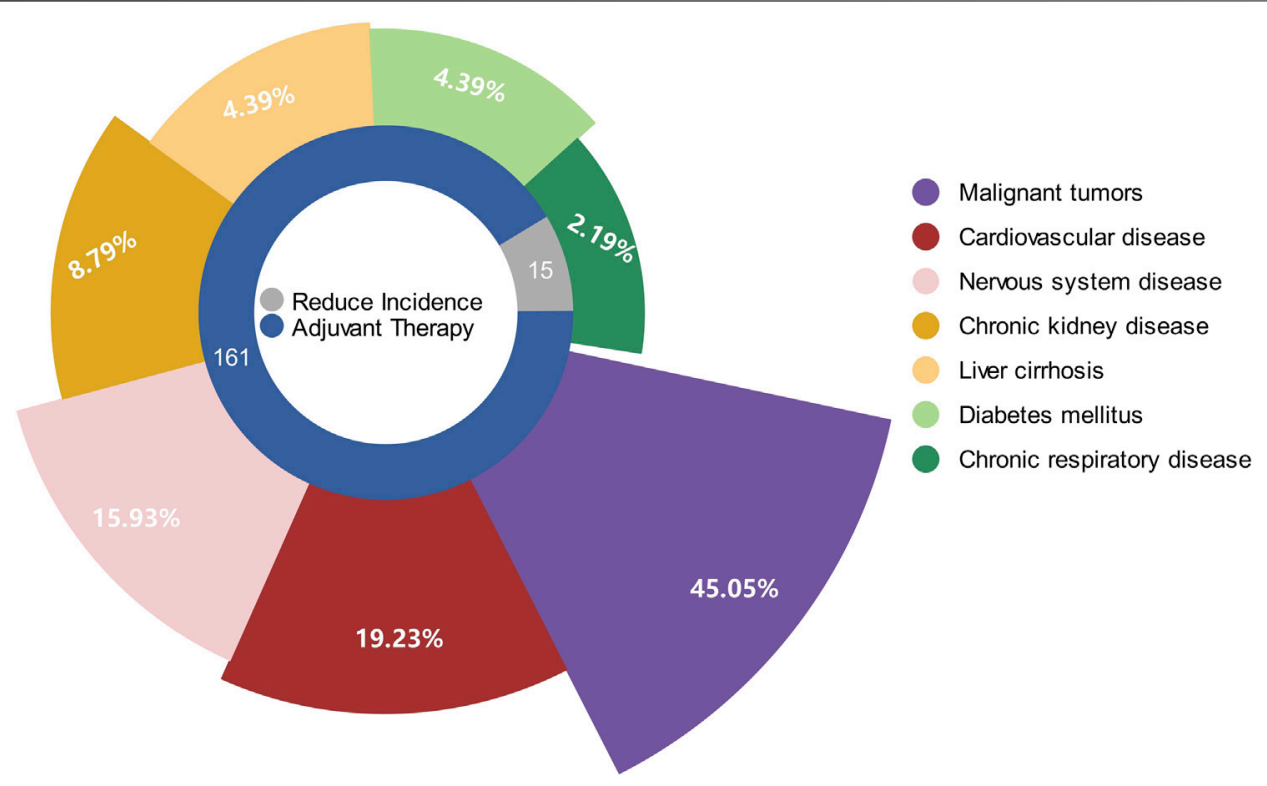

FIGURE 3 | Pie chart of the disease profile in the cohort studies. The inner circle of the pie chart shows the number of articles on TCM on the prevention and adjunctive treatment of NCDs. The outer circle of the pie chart shows the number of articles on each type of disease. NCD, non-communicable disease; TCM, traditional Chinese medicine.

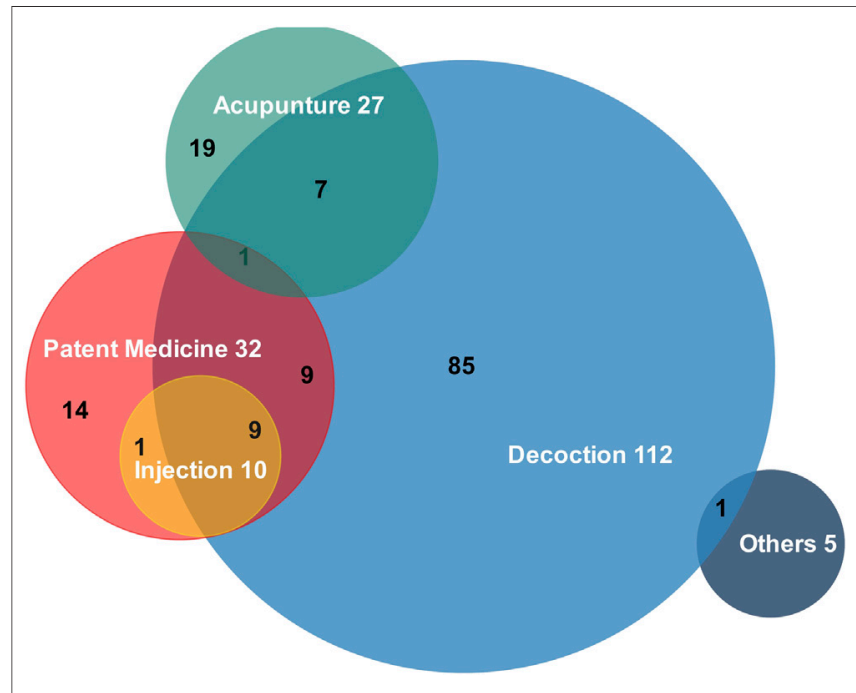

FIGURE 4 | Wayne diagram for the exposure factors. Different exposure factors are shown as circles. Simultaneous modes of exposure are shown as intersections. Other modes of exposure include manipulation, TCM formula transdermal patches, TCM formula enemas, and TCM formula plasters.

The white numbers are the total numbers of times of that exposure and the black numbers are the numbers of times of concomitant exposure.

exposure, and 5 articles used other modes of exposure, with simultaneous exposure (Figure 4). There were 48 articles with an undefined duration of TCM exposure in the exposure group, none of which defined the cohort migration of patients and the corresponding statistical processing. Significant differences were noted in the selection of formulas and herbs in different studies on the same disease or in the same cohort; use of multiple combinations and selection of formulas make demonstrating the use of specific prescriptions difficult.

Owing to the varying characteristics of different diseases and the differences in the study objectives, a large number of observation indicators were involved, and some of the studies were exploratory and did not define the primary endpoints. There were 103 studies (56.59\%) observing primary endpoint events (death, morbidity, etc.) and 65 studies (35.71\%) observing secondary endpoint events (such as re-hospitalization rates and laboratory indicators). There were 14 studies (7.69\%) observing only TCM syndrome evaluation, quality of life evaluation, or other subjective indicators.

The number of cohort studies on TCM for the prevention and treatment of malignant tumors is relatively large, and the selection of endpoint indicators is relatively uniform and representative. The main characteristics of the studies (published in English) are shown in Table 1. The main characteristics of another representative disease, the cardiovascular diseases, are shown in Supplementary Table S1.

\section{NOS Scoring of the Articles}

According to the eight rules of the NOS score, there were 11 articles $(6.04 \%)$ with a NOS score of 7, 27 articles (14.84\%) with a NOS score of 6, 67 articles (36.81\%) with a NOS score of 5, 49 articles $(26.92 \%)$ with a NOS score of 4,22 articles (12.09\%) with a NOS score of 3 , and 6 articles (3.30\%) with a NOS score of 2 , thus showing that the methodological quality of most of the cohort studies was low (Figure 5). 
TABLE 1 | Overview of cohort studies on the treatment of malignant tumors with traditional Chinese medicine (published in English).

\begin{tabular}{|c|c|c|c|c|c|c|c|c|}
\hline No & Diseases & Author & Year & $\begin{array}{l}\text { Sample } \\
\text { size }\end{array}$ & Exposure & Outcome & $\begin{array}{l}\text { Follow-up } \\
\text { time } \\
\text { (months) }\end{array}$ & $\begin{array}{l}\text { NOS } \\
\text { score }\end{array}$ \\
\hline 1 & Breast cancer & $\begin{array}{l}\text { Huang ChingHui, et al. } \\
\text { (Huang et al., 2019) }\end{array}$ & 2018 & 48,914 & Unspecified & Incidence of $\mathrm{CHF}(+)$ & $36-204^{a}$ & 5 \\
\hline 2 & Breast cancer & $\begin{array}{l}\text { Lee YiChiao, et al. (Lee } \\
\text { et al., 2020) }\end{array}$ & 2020 & 45 & Chinese herbal decoction & OS (+); laboratory index (-); QOL (+) & $40-52^{a}$ & 5 \\
\hline 3 & Breast cancer & $\begin{array}{l}\text { Lee YuanWen, et al. } \\
\text { (Lee et al., 2014) }\end{array}$ & 2014 & 729 & Unspecified & 10 Year mortality $(+)$ & $12-56^{a}$ & 5 \\
\hline 4 & Breast cancer & $\begin{array}{l}\text { Wang Yi, et al. (Wang } \\
\text { et al., 2020a) }\end{array}$ & 2020 & 148 & Chinese herbal decoction & $\begin{array}{l}2 \text { Year DFS (+); cumulative incidence } \\
\text { rate }(+) \text {; IDFS rate }(+) \text {; AEs }(-)\end{array}$ & $3-26^{a}$ & 7 \\
\hline 5 & Colorectal cancer & $\begin{array}{l}\text { Yeh MingHsien, et al. } \\
\text { (Yeh et al., 2020b) }\end{array}$ & 2020 & 535 & Chinese herbal medicine & $\begin{array}{l}\text { Survival rates }(+) \text {; subgroup analysis of } \\
\text { survival rates }( \pm)\end{array}$ & $36^{\int}$ & 4 \\
\hline 6 & Colorectal cancer & $\begin{array}{l}\text { Shao cui, et al. (Shao } \\
\text { et al., 2019) }\end{array}$ & 2019 & 191 & Chinese herbal decoction & OS $(+)$; risk of death $(+)$ & Unspecified & 5 \\
\hline 7 & Colorectal cancer & $\begin{array}{l}\text { Shi Qi, et al. (Shi et al., } \\
\text { 2017) }\end{array}$ & 2017 & 817 & Chinese herbal decoction & DFS (+); subgroup analysis of DFS $( \pm)$ & $23-143^{a}$ & 6 \\
\hline 8 & Colorectal cancer & $\begin{array}{l}\text { Xu Yun, et al. (Xu et al., } \\
\text { 2017) }\end{array}$ & 2017 & 312 & $\begin{array}{l}\text { Chinese herbal decoction; } \\
\text { Chinese patent medicine }\end{array}$ & $\begin{array}{l}\text { Recurrence and metastasis rate (+); OS } \\
(+) \text {; PFS (+) }\end{array}$ & $60-82^{a}$ & 6 \\
\hline 9 & Colorectal cancer & $\begin{array}{l}\text { Yang Yufei, et al. (Yang } \\
\text { et al., 2008) }\end{array}$ & 2008 & 222 & $\begin{array}{l}\text { Chinese herbal decoction } \\
\text { Chinese patent medicine }\end{array}$ & $\begin{array}{l}\text { Relapse and metastasis rates }(+) \text {; time } \\
\text { of relapse and metastasis }(+)\end{array}$ & $12-60^{a}$ & 5 \\
\hline 10 & Colorectal cancer & $\begin{array}{l}\text { Wang Yuli, et al. (Wang } \\
\text { et al., 2020b) }\end{array}$ & 2020 & 529 & Chinese herbal decoction & $\begin{array}{l}\text { Median PFS (-); subgroup analysis of } \\
\text { median PFS }( \pm)\end{array}$ & $12-72^{a}$ & 5 \\
\hline 11 & Colorectal cancer & $\begin{array}{l}\text { Zhang Tong, et al. } \\
\text { (Zhang et al., 2018) }\end{array}$ & 2018 & 335 & Chinese herbal decoction & Median OS $( \pm)$ & $11-39^{a}$ & 7 \\
\hline 12 & Gastric cancer & $\begin{array}{l}\text { Hung KuoFeng, et al. } \\
\text { (Hung et al., 2017) }\end{array}$ & 2017 & 1924 & Unspecified & OS $(+)$ & $12-170^{a}$ & 5 \\
\hline 13 & Gastric cancer & $\begin{array}{l}\text { Shu Peng, et al. (Shu } \\
\text { et al., 2019) }\end{array}$ & 2019 & 489 & Chinese herbal decoction & $\begin{array}{l}\text { DFS }(+) \text {; recurrence and metastasis } \\
\text { rate }(-) ; 5 \text { year survival rate }(+) \text {; QOL } \\
\text { and TCM syndromes }( \pm)\end{array}$ & $1-96^{a}$ & 6 \\
\hline 14 & $\begin{array}{l}\text { Gynecological } \\
\text { cancer }\end{array}$ & $\begin{array}{l}\text { Zeng Yingchun, et al. } \\
\text { (Zeng et al., 2018) }\end{array}$ & 2018 & 30 & Acupuncture & $\begin{array}{l}\text { Neurocognitive Test performance }(+) \text {; } \\
\mathrm{MRI} \text { and } \mathrm{MRS}(+)\end{array}$ & Unspecified & 5 \\
\hline 15 & $\begin{array}{l}\text { Head and neck } \\
\text { cancer }\end{array}$ & $\begin{array}{l}\text { Lin HungChe, et al. (Lin } \\
\text { et al., 2015) }\end{array}$ & 2015 & 5,636 & Chinese herbal decoction & Mortality rate $(+)$ & $1-132^{\mathrm{a}}$ & 6 \\
\hline 16 & Leukemia & $\begin{array}{l}\text { Tom Fleischer, et al. } \\
\text { (Fleischer et al., 2017) }\end{array}$ & 2017 & 498 & Unspecified & Survival rate $(+)$ & $0-160^{a}$ & 5 \\
\hline 17 & Leukemia & $\begin{array}{l}\text { Tom Fleischer, et al. } \\
\text { (Fleischer et al., 2016) }\end{array}$ & 2016 & 616 & Chinese herbal decoction & $\begin{array}{l}\text { HR of mortality (+); OS (+); most } \\
\text { commonly prescribed TCM }\end{array}$ & $28.68-34.2^{\iint}$ & 3 \\
\hline 18 & Leukemia & $\begin{array}{l}\text { Wang YuJun, et al. } \\
\text { (Wang et al., 2016b) }\end{array}$ & 2016 & 12,563 & Chinese herbal decoction & OS (+); expenditure $(-)$ & $12-120^{a}$ & 5 \\
\hline 19 & Liver cancer & $\begin{array}{l}\text { Liao YuehHsiang, et al. } \\
\text { (Liao et al., 2015) }\end{array}$ & 2015 & 127,237 & Unspecified & OS $(+)$ & $24-144^{a}$ & 5 \\
\hline 20 & Liver cancer & $\begin{array}{l}\text { Liao YuPei, et al. (Liao } \\
\text { et al., 2020) }\end{array}$ & 2020 & 14,729 & Unspecified & HR of mortality (+); survival rates $(+)$ & $24-108^{a}$ & 5 \\
\hline 21 & Liver cancer & $\begin{array}{l}\text { Sun Lingling, et al. (Sun } \\
\text { et al., 2018) }\end{array}$ & 2018 & 328 & Chinese herbal decoction & Median OS (+); HR of mortality (+) & $12-96^{a}$ & 4 \\
\hline 22 & Liver cancer & $\begin{array}{l}\text { Zhang Wei, et al. (Zhang } \\
\text { et al., 2014) }\end{array}$ & 2014 & 191 & Chinese patent medicine & Treatment effect (+); QOL (+) & $16-19^{a}$ & 3 \\
\hline 23 & Lung cancer & $\begin{array}{l}\text { Yeh MingHsien, et al. } \\
\text { (Yeh et al., 2020a) }\end{array}$ & 2020 & 1871 & Chinese herbal decoction & Survival rate $(+)$; mortality risk (+) & $3-167^{a}$ & 4 \\
\hline 24 & Lung cancer & $\begin{array}{l}\text { Shen HsuanShu, et al. } \\
\text { (Shen and Wen, 2018) }\end{array}$ & 2018 & 3,250 & Unspecified & Lung cancer specific mortality (+) & Unspecified & 4 \\
\hline 25 & Lung cancer & $\begin{array}{l}\text { Li ChiaLing, et al. (Li } \\
\text { et al., 2019) }\end{array}$ & 2019 & 1988 & Chinese herbal decoction & OS $(+) ;$ PFS $(+)$ & $1-84^{\mathrm{a}}$ & 5 \\
\hline 26 & Lung cancer & $\begin{array}{l}\text { Liao YuehHsiang, et al. } \\
\text { (Liao et al., 2017) }\end{array}$ & 2017 & 111,564 & Unspecified & $\begin{array}{l}\text { Survival rate }(+) \text {; risk factors and } \\
\text { protective factors analysis }\end{array}$ & $23.5-36.5^{\iint}$ & 5 \\
\hline 27 & Lung cancer & $\begin{array}{l}\text { Lin TsaiHui, et al. (Lin } \\
\text { et al., 2019a) }\end{array}$ & 2019 & 5,364 & Unspecified & $\begin{array}{l}\text { Incidence of lung cancer (+); risk factors } \\
\text { and protective factors analysis }\end{array}$ & Unspecified & 5 \\
\hline 28 & Lung cancer & $\begin{array}{l}\text { Liu Jie, et al. (J. Liu et al., } \\
\text { 2017) }\end{array}$ & 2017 & 474 & $\begin{array}{l}\text { Chinese herbal decoction } \\
\text { Chinese patent medicine } \\
\text { herbal injection }\end{array}$ & $\begin{array}{l}\text { OS (+); ORR (-); DCR (-); QOL (+); lung } \\
\text { cancer-related symptoms (+); AEs (+) }\end{array}$ & Unspecified & 7 \\
\hline 29 & Lung cancer & $\begin{array}{l}\text { Wang XueQian, et al. } \\
\text { (Wang et al., 2019) }\end{array}$ & 2019 & 503 & $\begin{array}{l}\text { Chinese patent medicine } \\
\text { Chinese herbal decoction }\end{array}$ & DFS (+); QOL (+) & $0-40^{a}$ & 3 \\
\hline 30 & Lung cancer & $\begin{array}{l}\text { Xiong ShaoQuan, et al. } \\
\text { (Xiong et al., 2018) }\end{array}$ & 2018 & 56 & Chinese herbal decoction & DCR (+); median PFS (+); AEs (-) & 12.3 & 5 \\
\hline
\end{tabular}


TABLE 1 | (Continued) Overview of cohort studies on the treatment of malignant tumors with traditional Chinese medicine (published in English).

\begin{tabular}{|c|c|c|c|c|c|c|c|c|}
\hline No & Diseases & Author & Year & $\begin{array}{l}\text { Sample } \\
\text { size }\end{array}$ & Exposure & Outcome & $\begin{array}{c}\text { Follow-up } \\
\text { time } \\
\text { (months) }\end{array}$ & $\begin{array}{l}\text { NOS } \\
\text { score }\end{array}$ \\
\hline 31 & Lung cancer & $\begin{array}{l}\text { Zhao XueYu, et al. } \\
\text { (Zhao et al., 2018) }\end{array}$ & 2018 & 67 & Chinese herbal decoction & Median OS (+); DFS (-) & $7-66^{a}$ & 5 \\
\hline 32 & Lung cancer & $\begin{array}{l}\text { Liu Rui, et al. (Liu et al., } \\
\text { 2015) }\end{array}$ & 2015 & 28 & $\begin{array}{l}\text { Chinese herbal decoction } \\
\text { Chinese patent medicine } \\
\text { herbal injection }\end{array}$ & Median PPS (+) & $8-27^{a}$ & 5 \\
\hline 33 & $\begin{array}{l}\text { Pancreatic } \\
\text { cancer }\end{array}$ & $\begin{array}{l}\text { Kuo YiTing, et al. (Kuo } \\
\text { et al., 2018) }\end{array}$ & 2017 & 772 & Unspecified & HR of mortality (+) & $12-180^{a}$ & 4 \\
\hline 34 & $\begin{array}{l}\text { Pancreatic } \\
\text { cancer }\end{array}$ & $\begin{array}{l}\text { Yang Xue, et al. (Yang } \\
\text { et al., 2015b) }\end{array}$ & 2015 & 107 & Chinese herbal decoction & Median OS (+) & $1-57^{\mathrm{a}}$ & 4 \\
\hline 35 & Prostate cancer & $\begin{array}{l}\text { Lin PoHung, et al. (Lin } \\
\text { et al., 2019b) }\end{array}$ & 2019 & 248 & Chinese herbal decoction & OS $(+)$ & $108-180^{\mathrm{a}}$ & 4 \\
\hline 36 & Prostate cancer & $\begin{array}{l}\text { Liu JuiMing, et al. (Liu } \\
\text { et al., 2016) }\end{array}$ & 2016 & 1,132 & Unspecified & Survival rate $(+)$ & $1-96^{\mathrm{a}}$ & 5 \\
\hline 37 & $\begin{array}{l}\text { BPH/Prostate } \\
\text { cancer }\end{array}$ & $\begin{array}{l}\text { Kuo YuJui, et al. (Kuo } \\
\text { et al., 2019) }\end{array}$ & 2019 & 5,812 & Chinese herbal decoction & Incidence of prostate cancer (+) & $60-192^{a}$ & 5 \\
\hline 38 & $\begin{array}{l}\text { Hepatitis B/Liver } \\
\text { cancer }\end{array}$ & $\begin{array}{l}\text { Tsai TzungYi, et al. (Tsai } \\
\text { et al., 2017) }\end{array}$ & 2017 & 21,020 & Unspecified & Incidence of liver cancer (+) & $0-180^{a}$ & 3 \\
\hline 39 & Colorectal cancer & $\begin{array}{l}\text { Michael McCulloch, } \\
\text { et al. (McCulloch et al., } \\
\text { 2011) }\end{array}$ & 2015 & 193 & Chinese herbal decoction & Survival rate $(+)$ & $0-120^{a}$ & 4 \\
\hline
\end{tabular}

Notes: AEs, Adverse Effects; APF, Alpha Fetoprotein; BPH, Benign Prostatic Hyperplasia; BMI, Body Mass Index; CHF, Chronic Heart Failure; COPD, Chronic Obstructive Pulmonary disease; DCR, disease Control Rate; DFS, Disease-free Survival; HR, Hazardous Ratio; IDFS, Invasive Disease-free Survival; KPS, Karnofsky Score; NOS, Newcastle-Ottawa Scale; OS, Overall Survival; PFS, Progression-free Survival; QOL, Quality of Life; RFS, Relapse Free Survival; SAS, Self-rating Anxiety Scale; SDS, Self-rating Depression Scale; TTP, Time to Tumor Progression.

${ }^{a}$ Follow-up time is estimated from the time of enrollment to the time of the last follow-up (months). $\iint$ Follow-up time is the mean follow-up time in the original article (months). (+) There is a statistically significant difference between the exposure and non-exposure groups; (-) there is no statistically significant difference between the exposure and non-exposure groups.



FIGURE 5 | Radar plot of NOS scores of the articles. The eight rules of the NOS were used as quadrants, with the maximum value being the total number of articles (182). The "comparability" item was given a score of $0-2$, and the remaining items were given a score of $0-1$. The positions of red dots indicate the scores. The closer to the boundary, the higher the score. The area encircled by the red lines represents the quality of the studies as a whole. The larger the area, the higher the quality. 


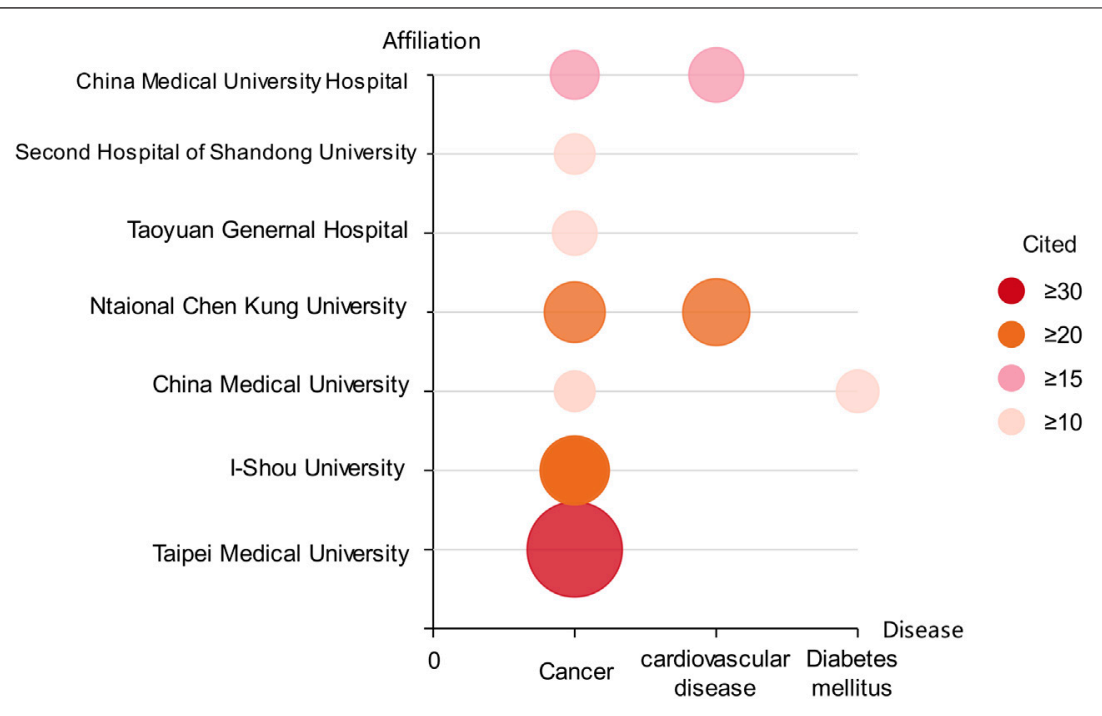

FIGURE 6 | Schematic representation of citations. Articles with citations $>10$ as is shown in the figure. The size and color of bubbles represent the volume of citations.

\section{Status of Citations}

The most frequently cited articles were breast cancer-related studies (citations $=38$ ), and most of the other articles were cited less than 10 times. The average number of citations in the field of oncology was relatively high. The 13 articles $(7.14 \%)$ with citations $>10$ were related to cancer, cardiovascular diseases, and diabetes mellitus, and most of the articles were published by affiliations in Chinese mainland and Taiwan (Figure 6).

\section{DISCUSSION}

Although cohort studies in the field of TCM were initiated relatively late in comparison to modern medicine (Nong et al., 2004), the number of such studies has rapidly increased and their quality has improved in the past decade. This study found that cohort studies on TCM for the prevention and treatment of NCDs had the following characteristics: 1) a cohort study on a malignant tumor is a hot and trending topic (45.05\%), with a high number of articles and citations; 2) the number of studies in Taiwan has been growing rapidly, with large sample sizes; 3 ) some of the studies were poorly reported and did not clearly describe the type of TCM formula, dosage form, exposure time, and rates of loss to follow-up; 4) The quality of studies published in English was generally higher than that of studies published in Chinese, but high-quality cohort studies were still rare. The mortality rate of malignant tumors was found to be high. When conducting cohort studies, clinical endpoints such as mortality can be observed in a relatively short follow-up time, which is convenient for controlling the rate of loss to follow-up. Therefore, the number of cohort studies on malignant tumors was relatively high. Meanwhile, the quality of reports, impact factors of journals in which the articles were published, and citations of articles on TCM for cancer prevention and treatment were all higher than the average level of cohort studies in TCM. While oncology professional teams attached importance to and actively conducted cohort studies, the prevention and treatment of cancer with TCM have also received much attention. The large number of studies and included cases in Taiwan was because Taiwan has a well-developed national insurance system (Huang et al., 2015) that keeps records of medical consultations, diagnoses, and prescription information of patients covered by the medical insurance, which facilitates large-sample cohort studies. Thus, the improvement of the Hospital Information System and the nationwide networked health insurance system is conducive for the preservation of patient disease information, acquisition of a larger number of cases, reduction of selection bias when researchers are not blinded and patient recall bias, as well as the conduct of high-quality clinical studies, especially cohort studies.

Some studies were self-defined as cohort studies, but were actually randomized controlled trials (RCTs), case-control studies, or crosssectional studies according to the reports (Yang et al., 2015a). The setting of exposure time varied widely among the studies, and there was no consensus or guideline on the exposure time of TCM, making it difficult to define whether the division between exposure and nonexposure was reasonable. The NOS scoring of all included articles revealed that articles with a score of four to five accounted for the largest proportion (63.73\%). The following items were scored relatively low, which led to a decrease in the quality of evidence: representativeness of the exposed cohort and adequacy of follow-up of the cohorts. Most current studies recruit patients through outpatient or inpatient services, which will introduce a selective bias due to differences in the condition of the subjects and reduce the representative characteristics of the exposed cohort. Compared with studies from hospitals, cohort studies with community-based sources may be more representative of the population (AHRQ Methods for Effective Health Care, 2013). However, as an exposure, TCM needs to be prescribed by doctors, making it easier to recruit hospital cases in terms of obtaining a sufficient sample size and follow-up. None of the included articles describe a blinded followup, and most of them do not indicate loss to follow-up. A possible reason for this is that some researchers neglect following up 
retrospective cohorts or neglect normatively reporting patients lost to follow-up. However, most of the exposure groups in the studies had a lower rate of loss to follow-up than the non-exposure groups, suggesting that TCM formulas may be effective in clinical settings.

In addition to implementing and reporting studies according to the clinical research implementation guidelines (von Elm et al., 2008; Chinese Physicians Association of Integrative Medicine, 2015) and NOS (Stang, 2010), quality control for TCM cohort studies can be carried out in the following ways: clarifying the characteristics of the study methodology, as well as implementing and reporting the study appropriately. While cohort studies are suitable for diseases with relatively rare outcomes, case-control studies are more suitable for diseases with rare or unclear exposure factors and infectious diseases (Dupépé et al., 2019), and cross-sectional studies are used to describe the current status. The clinical registration and publication of study protocols in accordance with the clinical trial registration platform can reduce wastage of academic resources, increase the standardization of study implementation, and improve the credibility of studies. Reasonable follow-up methods and timely data entry of follow-up data should be ensured. The quality of follow-up visits can be improved to a certain extent by choosing a follow-up method with higher compliance and formulating a standard operating procedure for the follow-up.

With methodological advances, many high-quality cohort studies (Mahmood et al., 2014; Syddall et al., 2019) have provided new evidence for clinical practice. Cohort studies focusing on TCM still lack groundbreaking results, despite explosive growth in the number of published articles and significant improvement in the research quality (Wang et al., 2016a). While a large number of randomized controlled studies have confirmed that TCM can improve symptoms of diseases or certain laboratory parameters (Hershman et al., 2018; Song et al., 2019; Zhang et al., 2020), the long-term benefits should but not have been adequately evaluated in cohort studies. Compared to the recent development of high-quality RCTs on TCM, high-quality cohort studies are slightly lacking. Our literature retrieval revealed that the ratio of published TCM cohort studies to RCTs is much lower than the ratio of internationally published cohort studies to RCTs, indicating that there is room for development of cohort studies in realworld research. Although cohort studies have a lower level of evidence compared with RCTs (Djulbegovic and Guyatt, 2017), they allow individual subjects to select the treatment according to their willingness and facilitate personalized TCM treatment, improve the external validity of clinical studies, and provide evidence for the treatment of major diseases in real-world studies. Cohort studies are not a simplification of randomized controlled studies. These studies require a study design with a clear objective; cohort studies differ from RCTs in the difficulty and duration of follow-up rather than the implementation of the blinding. Clarification on whether a particular study is an exploratory or a validation study can achieve reasonable conclusions to some extent.

This study innovatively provides a bibliographic analysis of cohort studies on the treatment of chronic NCDs with TCM, which is rapidly developing in recent years, and summarizes research hotspots and methods to improve research quality, thereby providing a landscape for researchers interested in conducting cohort studies. However, we judged the methodological quality based on the reports in the retrieved articles, and the original authors were not contacted to obtain a research protocol or relevant items in the design; therefore, there may be instances where the actual research methods do not match those reported by the articles (Lo et al., 2014).

In summary, cohort studies on TCM for the prevention and treatment of NCDs have shown progress in recent years, but the overall quality is still not sufficiently high to provide a concrete basis for clinical decision-making. Some articles have pointed out that TCM for the prevention and treatment of NCDs can reduce the symptoms of diseases and the adverse effects caused by conventional treatment options, as well as improve the quality of life. Many basic studies have verified the effect of TCM on the pathological mechanisms of various NCDs from the aspect of inflammatory pathways, oxidative stress, and cell apoptosis (Teng et al., 2018; Tian et al., 2019; Chen et al., 2020). Therefore, in order to confirm the findings of these studies, cohort studies should strengthen the specific drug and acupoint composition of reporting the exposure factors (such as a specific formula and acupoint selection), provide more details on TCM, and should be conducted in combination with other basic experiments. In the future, reasonable control of bias and non-inferiority testing of mortality and other endpoints (Leung et al., 2020) to verify that there is no statistically significant difference, followed by reasonable scale scoring, can highlight the advantages of TCM in the prevention and treatment of NCDs. How to strengthen the quality control of studies and reduce bias, and how to make studies closer to the current clinical situation of TCM to provide more valuable evidence for the development of TCM are both issues that need to be further addressed.

\section{AUTHOR CONTRIBUTIONS}

YL put on the reference collection, reference analysis, and writing of the manuscript. YL and $\mathrm{LH}$ contributed to the topic conception, manuscript revision, and decision to submit for publication and are the co-corresponding authors. YL, JC, and $\mathrm{HZ}$ contributed to reference analysis and helped in the revision of the manuscript.

\section{FUNDING}

This work was supported by Outstanding Youth Foundation of the National Natural Science Foundation (82022076), the Special Project for Outstanding Young Talents of the China Academy of Chinese Medical Sciences (ZZ13-YQ-001 and ZZ13-YQ-001-A1).

\section{SUPPLEMENTARY MATERIAL}

The Supplementary Material for this article can be found online at: https://www.frontiersin.org/articles/10.3389/fphar.2021.639860/ full\#supplementary-material. 


\section{REFERENCES}

AHRQ Methods for Effective Health Care (2013). "AHRQ methods for effective health Care," in Developing a protocol for observational comparative effectiveness research: a user"s guide. Editors P. Velentgas, N. A. Dreyer, P. Nourjah, S. R. Smith, and M. M. Torchia (Rockville, MD, United States: Agency for Healthcare Research and Quality (US) Copyright (c) 2013, Agency for Healthcare Research and Quality).

Chen, L., Lin, X., Fan, X., Qian, Y., Lv, Q., and Teng, H. (2020). Sonchus oleraceus Linn extract enhanced glucose homeostasis through the AMPK/Akt/GSK-3 $\beta$ signaling pathway in diabetic liver and HepG2 cell culture. Food Chem. Toxicol. 136, 111072. doi:10.1016/j.fct.2019.111072

Chinese Physicians Association of Integrative Medicine (2015). Clinical research methods guidelines for Chinese medicine and integrative medicine. Chin. J. Integrated Traditional West. Med. 8, 901-932.

Djulbegovic, B., and Guyatt, G. H. (2017). Progress in evidence-based medicine: a quarter century on. Lancet 390 (10092), 415-423. doi:10.1016/s0140-6736(16) $31592-6$

Dupépé, E. B., Kicielinski, K. P., Gordon, A. S., and Walters, B. C. (2019). What is a case-control study?. Neurosurgery 84 (4), 819-826. doi:10.1093/neuros/nyy590

Fleischer, T., Chang, T. T., Chiang, J. H., Hsieh, C. Y., Sun, M. F., and Yen, H. R. (2016). Integration of Chinese herbal medicine therapy improves survival of patients with chronic lymphocytic leukemia: a nationwide population-based cohort study. Medicine 95 (21), e3788. doi:10.1097/MD.0000000000003788

Fleischer, T., Chang, T. T., Chiang, J. H., Sun, M. F., and Yen, H. R. (2017). Improved survival with integration of Chinese herbal medicine therapy in patients with acute myeloid leukemia: a nationwide population-based cohort study. Integr. Cancer Ther. 16 (2), 156-164. doi:10.1177/1534735416664171

Hershman, D. L., Unger, J. M., Greenlee, H., Capodice, J. L., Lew, D. L., Darke, A. K., et al. (2018). Effect of acupuncture vs sham acupuncture or waitlist control on joint pain related to aromatase inhibitors among women with early-stage breast cancer: a randomized clinical trial. Jama 320 (2), 167-176. doi:10.1001/ jama.2018.8907

Hu, K., Guan, W. J., Bi, Y., Zhang, W., Li, L., Zhang, B., et al. (2020). Efficacy and safety of Lianhuaqingwen capsules, a repurposed Chinese herb, in patients with coronavirus disease 2019: a multicenter, prospective, randomized controlled trial. Phytomedicine, 153242. doi:10.1016/j.phymed.2020.153242

Huang, S. K., Wang, P. J., Tseng, W. F., Syu, F. K., Lee, M. C., Shih, R. L., et al. (2015). NHI-PharmaCloud in Taiwan--A preliminary evaluation using the REAIM framework and lessons learned. Int. J. Med. Inform. 84 (10), 817-825. doi:10.1016/j.ijmedinf.2015.06.001

Huang, X., Liu, G., Guo, J., and Su, Z. (2018). The PI3K/AKT pathway in obesity and type 2 diabetes. Int. J. Biol. Sci. 14 (11), 1483-1496. doi:10.7150/ijbs.27173

Huang, C. H., Chang, H. P., Su, S. Y., Chen, W. K., Chang, Y. J., Lee, Y. C., et al. (2019). Traditional Chinese medicine is associated with a decreased risk of heart failure in breast cancer patients receiving doxorubicin treatment. J. Ethnopharmacol 229, 15-21. doi:10.1016/j.jep.2018.09.030

Hung, K. F., Hsu, C. P., Chiang, J. H., Lin, H. J., Kuo, Y. T., Sun, M. F., et al. (2017). Complementary Chinese herbal medicine therapy improves survival of patients with gastric cancer in Taiwan: a nationwide retrospective matched-cohort study. J. Ethnopharmacol. 199, 168-174. doi:10.1016/j.jep.2017.02.004

Kuo, Y. T., Liao, H. H., Chiang, J. H., Wu, M. Y., Chen, B. C., Chang, C. M., et al. (2018). Complementary Chinese herbal medicine therapy improves survival of patients with pancreatic cancer in Taiwan: a nationwide population-based cohort study. Integr. Cancer Ther. 17 (2), 411-422. doi:10.1177/ 1534735417722224

Kuo, Y. J., Sung, F. C., Hsieh, P. F., Chang, H. P., Wu, K. L., and Wu, H. C. (2019). Metformin reduces prostate cancer risk among men with benign prostatic hyperplasia: a nationwide population-based cohort study. Cancer Med. 8 (5), 2514-2523. doi:10.1002/cam4.2025

Lancet, T. (2019). ICD-11. Lancet 393, 2275. doi:10.1016/s0140-6736(19)31205-x

Lee, Y. W., Chen, T. L., Shih, Y. R., Tsai, C. L., Chang, C. C., Liang, H. H., et al. (2014). Adjunctive traditional Chinese medicine therapy improves survival in patients with advanced breast cancer: a population-based study. Cancer 120 (9), 1338-1344. doi:10.1002/cncr.28579

Lee, Y.-C., Chen, Y.-H., Huang, Y.-C., Lee, Y.-F., and Tsai, M.-Y. (2020). Effectiveness of combined treatment with traditional Chinese medicine and western medicine on the prognosis of patients with breast cancer. J. Altern. Complement. Med. 26 (9), 835-842. doi:10.1089/acm.2019.0200

Leung, J. T., Barnes, S. L., Lo, S. T., and Leung, D. Y. (2020). Non-inferiority trials in cardiology: what clinicians need to know. Heart 106 (2), 99-104. doi:10.1136/ heartjnl-2019-315772

Li, C. L., Hsia, T. C., Li, C. H., Chen, K. J., Yang, Y. H., and Yang, S. T. (2019). Adjunctive traditional Chinese medicine improves survival in patients with advanced lung adenocarcinoma treated with first-line epidermal growth factor receptor (EGFR) tyrosine kinase inhibitors (TKIs): a nationwide, populationbased cohort study. Integr. Cancer Ther. 18, 1534735419827079. doi:10.1177/ 1534735419827079

Liao, Y. H., Lin, C. C., Lai, H. C., Chiang, J. H., Lin, J. G., and Li, T. C. (2015). Adjunctive traditional Chinese medicine therapy improves survival of liver cancer patients. Liver Int. 35 (12), 2595-2602. doi:10.1111/liv.12847

Liao, Y. H., Li, C. I., Lin, C. C., Lin, J. G., Chiang, J. H., and Li, T. C. (2017). Traditional Chinese medicine as adjunctive therapy improves the long-term survival of lung cancer patients. J. Cancer Res. Clin. Oncol. 143 (12), 2425-2435. doi:10.1007/s00432-017-2491-6

Liao, Y.-P., Kung, P.-T., Wang, Y.-H., Chu, Y.-R., Kao, S.-T., and Tsai, W.-C. (2020). Effects and relative factors of adjunctive Chinese medicine therapy on survival of hepatocellular carcinoma patients: a retrospective cohort study in taiwan. Integr. Cancer Ther. 19, 153473542091527. doi:10.1177/ 1534735420915275

Lin, H. C., Lin, C. L., Huang, W. Y., Shangkuan, W. C., Kang, B. H., Chu, Y. H., et al. (2015). The use of adjunctive traditional Chinese medicine therapy and survival outcome in patients with head and neck cancer: a nationwide population-based cohort study. QJM 108 (12), 959-965. doi:10.1093/ qjmed/hcv079

Lin, T. H., Chen, S. I., Su, Y. C., Lin, M. C., Lin, H. J., and Huang, S. T. (2019a). Conventional Western treatment combined with Chinese herbal medicine alleviates the progressive risk of lung cancer in patients with chronic obstructive pulmonary disease: a nationwide retrospective cohort study. Front. Pharmacol. 10, 987. doi:10.3389/fphar.2019.00987

Lin, P.-H., Lin, S.-K., Hsu, R.-J., Pang, S.-T., Chuang, C.-K., Chang, Y.-H., et al. (2019b). Spirit-quieting traditional Chinese medicine may improve survival in prostate cancer patients with depression. Jcm 8 (2), 218. doi:10.3390/ jcm8020218

Liu, J. P. (2007). Evidence-based medicine and the evaluation of therapeutic efficacy in traditional Chinese medicine. J. Traditional Chin. Med. 1, 26-28.

Liu, R., He, S. L., Zhao, Y. C., Zheng, H. G., Li, C. H., Bao, Y. J., et al. (2015). Chinese herbal decoction based on syndrome differentiation as maintenance therapy in patients with extensive-stage small-cell lung cancer: an exploratory and small prospective cohort study. Evid. Based Complement. Alternat Med. 2015, 601067. doi:10.1155/2015/601067

Liu, J. M., Lin, P. H., Hsu, R. J., Chang, Y. H., Cheng, K. C., Pang, S. T., et al. (2016). Complementary traditional Chinese medicine therapy improves survival in patients with metastatic prostate cancer. Medicine 95 (31), e4475. doi:10.1097/ MD.0000000000004475

Liu, J., Lin, H. S., Hou, W., Hua, B. J., Zhang, P. T., Li, J., et al. (2017). Comprehensive treatment with Chinese medicine in patients with advanced non-small cell lung cancer: a multicenter, prospective, cohort study. Chin. J. Integr. Med. 23 (10), 733-739. doi:10.1007/s11655-016-2737-1

Lo, C. K., Mertz, D., and Loeb, M. (2014). Newcastle-Ottawa Scale: comparing reviewers' to authors' assessments. BMC Med. Res. Methodol. 14, 45. doi:10. 1186/1471-2288-14-45

Ma, N., Zhang, Z., Liao, F., Jiang, T., and Tu, Y. (2020). The birth of artemisinin. Pharmacol. Ther. 216, 107658. doi:10.1016/j.pharmthera.2020.107658

Mahmood, S. S., Levy, D., Vasan, R. S., and Wang, T. J. (2014). The Framingham Heart Study and the epidemiology of cardiovascular disease: a historical perspective. Lancet 383 (9921), 999-1008. doi:10.1016/s0140-6736(13)61752-3

McCulloch, M., Broffman, M., van der Laan, M., Hubbard, A., Kushi, L., Abrams, D. I., et al. (2011). Colon cancer survival with herbal medicine and vitamins combined with standard therapy in a whole-systems approach: ten-year followup data analyzed with marginal structural models and propensity score methods. Integr. Cancer Ther. 10 (3), 240-259. doi:10.1177/1534735411406539

Newman, D. J., and Cragg, G. M. (2020). Natural products as sources of new drugs over the nearly four decades from 01/1981 to 09/2019. J. Nat. Prod. 83 (3), 770-803. doi:10.1021/acs.jnatprod.9b01285 
Nong, Y. B., Lin, Q., Duan, W. H., and Yang, H. L. (2004). Construction of a Cox proportional risk regression model of long-term prognostic factors of acute myocardial infarction from a retrospective cohort study. Chin. J. Integrated Traditional West. Med. 9, 781-784.

Omran, A. R. (1971). The epidemiologic transition. A theory of the epidemiology of population change. Milbank Mem. Fund Q. 49 (4), 509-538. doi:10.2307/ 3349375

Organization, W. H. (2018a). Global health estimates 2016: deaths by cause, age, sex, by country and by region, 2000-2016. Geneva, Switzerland: WHO http:// awareness.who.int/healthinfo/global_burden_disease/estimates/en/.

Organization, W. H. (2018b). Noncommunicable diseases country profiles 2018. Geneva, Switzerland: WHO, https://www.who.int/nmh/publications/ncdprofiles-2018/en/.

Shao, C., Zuo, Q., Lin, J., Yu, R. J., Fu, Y., Xiao, M., et al. Effect of Chinese herbal medicine on the survival of colorectal cancer patients with liver-limited metastases: a retrospective cohort study, 2008 to 2017. Integr. Cancer therapies (2019) 18, 1534735419883687. doi:10.1177/1534735419883687

Shen, H. S., and Wen, S. H. (2018). Effect of early use of Chinese herbal products on mortality rate in patients with lung cancer. J. Ethnopharmacol 211, 1-8. doi:10. 1016/j.jep.2017.09.025

Shi, Q., Liu, S., Li, W., Zong, S., Han, S., Yang, W., et al. (2017). Exploring the medication duration based on the effect of traditional Chinese medicine on postoperative stage I-III colorectal patients: a retrospective cohort study. Oncotarget 8 (8), 13488. doi:10.18632/oncotarget.14567

Shu, P., Tang, H., Zhou, B., Wang, R., Xu, Y., Shao, J., et al. (2019). Effect of Yiqi Huayu Jiedu decoction on stages II and III gastric cancer: a multicenter, prospective, cohort study. Medicine 98 (47), e17875. doi:10.1097/MD. 0000000000017875

Song, Y., Yao, C., Yao, Y., Han, H., Zhao, X., Yu, K., et al. (2019). XueBijing injection versus placebo for critically ill patients with severe communityacquired pneumonia: a randomized controlled trial. Crit. Care Med. 47 (9), e735-e743. doi: $10.1097 / \mathrm{ccm} .0000000000003842$

Stang, A. (2010). Critical evaluation of the Newcastle-Ottawa scale for the assessment of the quality of nonrandomized studies in meta-analyses. Eur. J. Epidemiol. 25 (9), 603-605. doi:10.1007/s10654-010-9491-Z

Sun, L., Fahey, P., Zhu, X., Ng, W., Chen, Z. P., Qiu, Y., et al. (2018). A cohort study to examine the use of Chinese herbal medicine in combination with conventional therapies for patients with hepatocellular carcinoma in China. Integr. Cancer Ther. 17 (3), 902-911. doi:10.1177/ 1534735418775819

Syddall, H. E., Simmonds, S. J., Carter, S. A., Robinson, S. M., Dennison, E. M., and Cooper, C. (2019). The hertfordshire cohort study: an overview. F1000Res 8, 82. doi:10.12688/f1000research.17457.1

Teng, H., Yuan, B., Gothai, S., Arulselvan, P., Song, X., and Chen, L. (2018). Dietary triterpenes in the treatment of type 2 diabetes: to date. Trends Food Sci. Tech. 72, 34-44. doi:10.1016/j.tifs.2017.11.012

Tian, J., Popal, M. S., Zhao, Y., Liu, Y., Chen, K., and Liu, Y. (2019). Interplay between exosomes and autophagy in cardiovascular diseases: novel promising target for diagnostic and therapeutic application. Aging Dis. 10 (6), 1302-1310. doi:10.14336/ad.2018.1020

Tsai, T. Y., Livneh, H., Hung, T. H., Lin, I. H., Lu, M. C., and Yeh, C. C. (2017). Associations between prescribed Chinese herbal medicine and risk of hepatocellular carcinoma in patients with chronic hepatitis $\mathrm{B}$ : a nationwide population-based cohort study. BMJ Open 7 (1), e014571. doi:10.1136/ bmjopen-2016-014571

von Elm, E., Altman, D. G., Egger, M., Pocock, S. J., Gøtzsche, P. C., and Vandenbroucke, J. P. (2008). The Strengthening the Reporting of Observational Studies in Epidemiology (STROBE) statement: guidelines for reporting observational studies. J. Clin. Epidemiol. 61 (4), 344-349. doi:10.1016/ j.jclinepi.2007.11.008

Wagner, K. H., and Brath, H. (2012). A global view on the development of non communicable diseases. Prev. Med. 54 (Suppl. 1), S38-S41. doi:10.1016/j.ypmed. 2011.11.012

Wang, M., Wang, J. H., and Zhang, F. (2016a). Methodological quality evaluation of traditional Chinese medicine efficacy evaluation cohort studies. J. Traditional Chin. Med. 16, 1379-1383.

Wang, Y. J., Liao, C. C., Chen, H. J., Hsieh, C. L., and Li, T. C. (2016b). The effectiveness of traditional Chinese medicine in treating patients with leukemia.
Evid. Based Complement. Alternat Med. 2016, 8394850. doi:10.1155/2016/ 8394850

Wang, X. Q., Zhang, Y., Hou, W., Wang, Y. T., Zheng, J. B., Li, J., et al. (2019). Association between Chinese medicine therapy and survival outcomes in postoperative patients with nsclc: a multicenter, prospective, cohort study. Chin. J. Integr. Med. 25 (11), 812-819. doi:10.1007/s11655-019-3168-6

Wang, Y., Li, J. W., Qin, Y. N., Sun, C. P., Chen, J. J., Ruan, Y. Y., et al. (2020a). Clinical observation on the effect of Chinese medicine-"TCM formula" intervention on recurrence and metastasis of triple negative breast cancer. Complement. Ther. Med. 52, 102456. doi:10.1016/j.ctim.2020.102456

Wang, Y., Liu, P., Fang, Y., Tian, J., Li, S., Xu, J., et al. (2020b). The effect of long-term traditional Chinese medicine treatment on survival time of colorectal cancer based on propensity score matching: a retrospective cohort study. Evidence-Based Complement. Altern. Med. 2020, 7023420. doi:10.1155/2020/7023420

Xiong, S. Q., Li, Y. L., Wang, S. M., Jin, S., Luo, Q. Y., Ding, Q., et al. (2018). [Cohort study of EGFR-TKIs combined with traditional Chinese medicine and single EGFR-TKIs for advanced NSCLC (Non-small cell lung cancer)]. Sichuan Da Xue Xue Bao Yi Xue Ban 49 (4), 566-569.

Xu, Y., Mao, J. J., Sun, L., Yang, L., Li, J., Hao, Y., et al. (2017). Association between use of traditional Chinese medicine herbal therapy and survival outcomes in patients with stage II and III colorectal cancer: a multicenter prospective cohort study. J. Natl. Cancer Inst. Monogr. 2017 (52), lgx015. doi:10.1093/ jncimonographs/lgx015

Yang, Y. F., Ge, J. Z., Wu, Y., Xu, Y., Liang, B. Y., Luo, L., et al. (2008). Cohort study on the effect of a combined treatment of traditional Chinese medicine and Western medicine on the relapse and metastasis of 222 patients with stage II and III colorectal cancer after radical operation. Chin. J. Integr. Med. 14 (4), 251-256. doi:10.1007/s11655-008-0251-9

Yang, T. Y., Wei, J. C., Lee, M. Y., Chen, C. M., and Ueng, K. C. (2012). A randomized, double-blind, placebo-controlled study to evaluate the efficacy and tolerability of Fufang Danshen (Salvia miltiorrhiza) as add-on antihypertensive therapy in Taiwanese patients with uncontrolled hypertension. Phytother Res. 26 (2), 291-298. doi:10.1002/ptr.3548

Yang, P. R., Shih, W. T., Chu, Y. H., Chen, P. C., and Wu, C. Y. (2015a). Frequency and co-prescription pattern of Chinese herbal products for hypertension in Taiwan: a Cohort study. BMC Complement. Altern. Med. 15, 163. doi:10.1186/ s12906-015-0690-8

Yang, X., Hao, J., Zhu, C. H., Niu, Y. Y., Ding, X. L., Liu, C., et al. (2015b). Survival benefits of Western and traditional Chinese medicine treatment for patients with pancreatic cancer. Medicine 94 (26), e1008. doi:10.1097/MD. 0000000000001008

Yeh, M. H., Wu, H. C., Lin, N. W., Hsieh, J. J., Yeh, J. W., Chiu, H. P., et al. (2020a). Long-term use of combined conventional medicine and Chinese herbal medicine decreases the mortality risk of patients with lung cancer. Complement. Ther. Med. 52, 102427. doi:10.1016/j.ctim.2020.102427

Yeh, M. H., Chiu, H. P., Wu, M. C., Koo, M., Lin, N. W., Liao, K. K., et al. (2020b). Integrated Chinese herbal medicine and western medicine on the survival in patients with colorectal cancer: a retrospective study of medical records. Evid. Based Complement. Alternat Med. 2020, 4561040. doi:10.1155/2020/4561040

Zeng, Y., Cheng, A. S. K., Song, T., Sheng, X., Wang, S., Xie, J., et al. (2018). Effects of acupuncture on cancer-related cognitive impairment in Chinese gynecological cancer patients: a pilot cohort study. Integr. Cancer Ther. 17 (3), 737-746. doi:10.1177/1534735418777109

Zhang, L., and Wei, W. (2020). Anti-inflammatory and immunoregulatory effects of paeoniflorin and total glucosides of paeony. Pharmacol. Ther. 207, 107452. doi:10.1016/j.pharmthera.2019.107452

Zhang, W., Ma, Y. Z., Song, L., Wang, C. H., Qi, T. G., and Shao, G. R. (2014). Effect of cantharidins in chemotherapy for hepatoma: a retrospective cohort study. Am. J. Chin. Med. 42 (03), 561-567. doi:10.1142/S0192415X14500360

Zhang, T., He, W. T., Zi, M. J., Song, G., Yi, D. H., and Yang, Y. F. (2018). Cohort study on prognosis of patients with metastatic colorectal cancer treated with integrated Chinese and western medicine. Chin. J. Integr. Med. 24 (8), 573-578. doi:10.1007/s11655-018-2980-0

Zhang, T., He, W. T., and Fei, Y. T. (2019). Bias control in interventional cohort studies and its peculiarities in the field of traditional Chinese medicine. J. Traditional Chin. Med. (11), 923-927.

Zhang, D. Y., Cheng, Y. B., Guo, Q. H., Shan, X. L., Wei, F. F., Lu, F., et al. (2020). Treatment of masked hypertension with a Chinese herbal formula: a 
randomized, placebo-controlled trial. Circulation 142 (19), 1821-1830. doi:10. 1161/circulationaha.120.046685

Zhao, X., Dai, X., Wang, S., Yang, T., Yan, Y., Zhu, G., et al. (2018). Traditional Chinese medicine integrated with chemotherapy for stage II-IIIA patients with non-small-cell lung cancer after radical surgery: a retrospective clinical analysis with small sample size. Evid. Based Complement. Alternat Med. 2018, 4369027. doi:10.1155/2018/4369027

Zhao, C., Li, S., Zhang, J., Huang, Y., Zhang, L., Zhao, F., et al. (2020). Current state and future perspective of cardiovascular medicines derived from natural products. Pharmacol. Ther. 216, 107698. doi:10.1016/j.pharmthera.2020. 107698
Conflict of Interest: The authors declare that the research was conducted in the absence of any commercial or financial relationships that could be construed as a potential conflict of interest.

Copyright () $2021 \mathrm{Li}$, Liu, Cui, Zhao, Liu and Huang. This is an open-access article distributed under the terms of the Creative Commons Attribution License (CC BY). The use, distribution or reproduction in other forums is permitted, provided the original author(s) and the copyright owner(s) are credited and that the original publication in this journal is cited, in accordance with accepted academic practice. No use, distribution or reproduction is permitted which does not comply with these terms. 